\title{
FE analysis of conceptual hybrid composite endodontic post designs in anterior teeth
}

DOI:

10.1016/j.dental.2018.04.004

\section{Document Version}

Accepted author manuscript

Link to publication record in Manchester Research Explorer

\section{Citation for published version (APA):}

Gloria, A., Maietta, S., Martorelli, M., Lanzotti, A., Watts, D. C., \& Ausiello, P. (2018). FE analysis of conceptual hybrid composite endodontic post designs in anterior teeth. Dental Materials.

https://doi.org/10.1016/j.dental.2018.04.004

\section{Published in:}

Dental Materials

\section{Citing this paper}

Please note that where the full-text provided on Manchester Research Explorer is the Author Accepted Manuscript or Proof version this may differ from the final Published version. If citing, it is advised that you check and use the publisher's definitive version.

\section{General rights}

Copyright and moral rights for the publications made accessible in the Research Explorer are retained by the authors and/or other copyright owners and it is a condition of accessing publications that users recognise and abide by the legal requirements associated with these rights.

\section{Takedown policy}

If you believe that this document breaches copyright please refer to the University of Manchester's Takedown Procedures [http://man.ac.uk/04Y6Bo] or contact uml.scholarlycommunications@manchester.ac.uk providing relevant details, so we can investigate your claim.

\section{OPEN ACCESS}


FE Analysis of Conceptual Hybrid Composite Endodontic Post Designs in Anterior Teeth

Antonio GLORIA ${ }^{\mathrm{a},{ }^{*}, \text { Saverio MAIETTA }}{ }^{\mathrm{b},{ }^{*}}$, Massimo MARTORELLI ${ }^{\mathrm{b}}$, Antonio LANZOTTI ${ }^{\mathrm{b}}$, David C WATTS $^{\mathrm{c}}$, Pietro AUSIELLO $^{\mathrm{d}}$

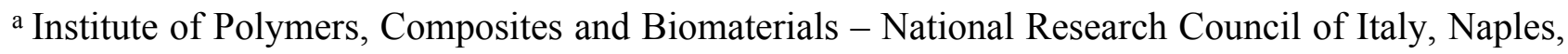
Italy

b Department of Industrial Engineering, Fraunhofer JL IDEAS - University of Naples Federico II, Italy

c School of Medical Sciences and Photon Science Institute, University of Manchester, United Kingdom

d School of Dentistry - University of Naples Federico II, Italy

*corresponding author: angloria@unina.it and smaietta@unina.it 


\title{
FE Analysis of Conceptual Hybrid Composite Endodontic Post Designs in Anterior Teeth
}

\begin{abstract}
Objectives: To assess conceptual designs of dental posts consisting of polyetherimide (PEI) reinforced with carbon $(\mathrm{C})$ and glass $(\mathrm{G})$ glass fibers in endodontically treated anterior teeth.
\end{abstract}

Methods: 3D tessellated CAD and geometric models of endodontically treated anterior teeth were generated from Micro-CT scan images. Model C-G/PEI composite posts with different Young's moduli were analyzed by Finite Element (FE) methods: post A $(57.7 \mathrm{GPa})$, post B (31.6 GPa), post $\mathrm{C}$ (from 57.7 to $9.0 \mathrm{GPa}$ in the coronal-apical direction). A load of $50 \mathrm{~N}$ was applied at $45^{\circ}$ to the longitudinal axis of the tooth, acting on the palatal surface of the crown. The maximum principal stress distribution was determined along the post and at the interface between the post and the surrounding structure.

Results: Post C, with Young's modulus decreasing from 57.7 to $9.0 \mathrm{GPa}$ in the coronal-apical direction, reduced the maximum principal stress distribution in the restored tooth. Post $\mathrm{C}$ gave reduced stress and the most uniform stress distribution with no stress concentration, compared to the other C-G/PEI composite posts.

Significance: The FE analysis confirmed the ability of the functionally graded post to dissipate stress from the coronal to the apical end. Hence actual (physical) C-G/PEI posts could permit optimization of stress distributions in endodontically treated anterior teeth.

Keywords: Image Analysis; CAD; Design; Finite Element Analysis; Dental Materials; Endodontic Treatment 


\section{Introduction}

The restoration of endodontically treated teeth represents a great challenge especially where there has been a significant loss of tooth structure [1-3]. Adhesive techniques are considered essential in such treatment [4-6] and the endodontic procedures required are often accompanied by a decrease in tooth rigidity $[7,8]$. Even though in many cases adhesives may be employed without a post, in larger posterior teeth the use of posts should be considered [9-12]. For anterior endodontically treated teeth with a veneer, fracture resistance should be improved by employing a cemented fiber post [13].

Post/core endodontic treatment utilizes a range of industrially constructed posts with varied materials, sizes and shapes for clinical use by endodontists. Collectively these variables may be designated post designs. There has been a significant trend away from traditional cast metal or ceramic posts towards the use of glass fiber composite posts that exhibit a closer match between the post stiffness, or elastic modulus, and the elastic modulus of the residual tooth structure.

Despite major differences, there are some parallels between the design criteria and challenges of endodontic post therapy and those involved with: (a) dental implant designs and (b) femoral prosthesis designs in total hip replacement surgery or arthroplasty. In all such cases, biomechanical stresses generated in functional service will affect the retention and stability depending upon, inter alia, the relative biomaterial/host tissue elastic moduli and the residual thicknesses of the hard tissue host.

As in many other areas of bioengineering, Finite Element (FE) analysis has proved beneficial in creating computational model scenarios that facilitate exploration of the effects of different design variables, whether in endodontics, implantology or arthroplasty. FE analyses demonstrated a nonphysiological strain and stress distribution due to the presence of an endodontic post [14-17]. Moreover, many analyses showed different mechanical behavior for endodontically treated anterior teeth compared to sound teeth [18].

FE analysis has been already used to assess the influence of the shape, length, diameter and stiffness of the post as well as of the "ferrule effect" [4,19-29]. In particular, a study on the mechanical behavior of endodontically treated canine teeth provided interesting results in terms of stress distribution, evidencing the synergistic contribution of the ferrule effect and the specific materialshape combination of the post [29]. 
Different dental post-core systems have been proposed [30]. Metal posts were initially utilized. However, the great mismatch between the elastic modulus of metal posts and surrounding structures generally leads to stress concentration and root fracture [30]. Consequently, posts with different shape, size and materials were developed [30]. A more favourable stress distribution may be obtained using glass fiber-reinforced posts, which have an elastic modulus (45.7-53.8 GPa) [30,31] lower than those of metal posts (110 GPa for titanium and $95 \mathrm{GPa}$ for gold) [30,32] and higher than that of dentin $(18.6 \mathrm{GPa})[30,33]$. It is well known that stress concentration generally occurs at the apical and cervical regions of the tooth and that flexible posts cause stress concentrations in dentin, whereas rigid posts concentrate stresses at the interfaces. To optimize stress distribution, a post should possess a functionally graded stiffness decreasing from the coronal part to the apical end [30,34]. This might be achieved with an inhomogenous post design [34].

In arthroplasty, recent studies [35,36] have investigated certain hybrid composite materials incorporating a fiber-reinforced matrix of polyether imide (PEI). These PEI hybrid composites have been fabricated with different shapes and functionally graded stiffness along the axial length. Although fabrication of the comparatively large femoral prostheses in a hybrid design is relatively straightforward, emerging micro-fabrication techniques should make it possible to construct endodontic posts with analogous hybrid PEI composite designs. This possibility is the motivation for the present study, where we consider a number of conceptual post designs. These are based upon the concept of a PEI matrix reinforced with either carbon (C) or glass (G) fibers, including an inhomogenous post-design with functionally graded stiffness decreasing in the coronal to apical direction.

The aim was to assess the stress distribution along the post and at the interface between the post and the surrounding structure in endodontically treated canine teeth when using three different C-G/PEI posts. 


\section{Materials and Methods}

\subsection{Post material and design}

Three conceptual designs of hybrid composite posts consisting of a polyetherimide (PEI) matrix reinforced with carbon $(\mathrm{C})$ and glass $(\mathrm{G})$ fibers were considered:

Post A (C-G/PEI with a Young's modulus of $57.7 \mathrm{GPa})$,

Post B (C-G/PEI with a Young's modulus of $31.6 \mathrm{GPa})$,

Post $\mathrm{C}(\mathrm{C}-\mathrm{G} / \mathrm{PEI}$ with a Young's Modulus varying from 57.7 to $9.0 \mathrm{GPa}$ in the coronal-apical direction).

All the composite posts with conical-tapered shape had the following geometrical features: total length - $15 \mathrm{~mm}$, length on coronal part (cylindric) - $7 \mathrm{~mm}$, length on conicity part $-8 \mathrm{~mm}$, coronal diameters - Ø $1.05-\varnothing 1.25-\varnothing 1.45$, apical diameters - Ø $0.55-\varnothing 0.75-\varnothing 0.95$.

The approach towards the conceptual post design was carried out according to the experimental results obtained in a previous study on the development of composite stem for hip prosthesis with tailored properties along the head-tip direction $[35,36]$. This device was constructed using hand layup techniques, compression molding and water jet technology $[35,36]$.

Post A and post B corresponded to Zone I and Zone II of the previous developed device [35,36], whereas post $\mathrm{C}$ was a C-G/PEI post with a Young's Modulus decreasing from 57.7 to $9.05 \mathrm{GPa}$ in the coronal-apical direction. FE analysis, ply drop-off and stacking sequence were considered to obtain devices with the required properties $[35,36]$.

\subsection{Generation of a tooth solid model}

A micro-CT scanner system (Bruker microCT, Kontich, Belgium) was used to digitize an intact canine, taking into account previously adopted methodologies from the scanning through the tessellated model $[4,29,37]$. A total of 951 slices were collected at a resolution of $1024 \times 1024$ pixels [4]. Anyway, only 252 slices were considered as already specified [4].

Briefly, image data sets were processed via ScanIP ${ }^{\circledR}$ (3.2, Simpleware Ltd., Exeter, UK). Image segmentation and filtering procedures were used [4,29,37], and the 3D tessellated model of the tooth was created [4,29]. As reported [4,29], blending operations were performed through cross sections to convert tessellated models into surfaces. These operations were carried out using SolidWorks ${ }^{\circledR} 2017$ (Dassault Systemes, Paris, France) CAD system, where the ScanTo3D ${ }^{\circledR}$ add-in allowed to manage the tessellated geometry [4]. Lofting surfaces were created and the congruence of interfacial boundaries of tooth tissues was ensured [4,29]. 
Tooth geometry, crown preparation, tooth reduction, as well as the system of coordinates, where the geometrical model was located, were reported previously [29].

Three different geometric models of the restored tooth were created starting from the sound tooth model [29]. Three C-G/PEI posts were designed: posts A, B and C (15 mm in length) with a conical-tapered shape.

A cement layer $(0.1 \mathrm{~mm}$ in thickness) was added between the prepared crown and the abutment. The cement was added between the post and the root in the canal. Furthermore, the periodontal ligament $(0.25 \mathrm{~mm}$ in thickness $)$ was modeled around the root for all models.

\subsection{Numerical simulation}

Using the IGES format, the geometric models of endodontically treated anterior teeth were imported into HyperMesh ${ }^{\circledR}$ (HyperWorks ${ }^{\circledR}$ - 14.0, Altair Engineering Inc., Troy, Michigan, USA), FE pre-processor which allows to manage the generation of the largest, most complex models, starting with the import of CAD geometry to exporting ready-to-run solver file.

Three models were built-up and analyzed using FE analysis:

Model A (a tooth with Post A),

Model B (a tooth with Post B),

Model C (a tooth with Post C).

Each component of the tooth model was defined in terms of Young's modulus and Poisson's ratio (Table 1).

\begin{tabular}{lll}
\hline Component & Young's modulus (GPa) & Poisson's ratio \\
\hline Lithium disilicate crown & 70 & 0.30 \\
Crown cement & 8.2 & 0.30 \\
Abutment & 12 & 0.30 \\
Post A & 57.7 & 0.30 \\
Post B & 31.6 & 0.30 \\
Post C & $57.7-9.0^{*}$ & 0.30 \\
Post cement & 8.2 & 0.30 \\
Root & 18.6 & 0.31 \\
Periodontal ligament & $0.15\left(\mathrm{x} \mathrm{10^{-3 }}\right)$ & 0.45 \\
Food (apple pulp) & $3.41\left(\mathrm{x} 10^{-3}\right)$ & 0.10 \\
\hline
\end{tabular}

Table 1 - Mechanical properties: Young's modulus and Poisson's ratio. [29]. * These values varied in the coronal-apical direction according to the different regions in the design of post $\mathrm{C}$. 
Taking into account previous methodology [29], the 3D mesh was created and each tooth model was divided into 3D solid CTETRA elements with four grid points, a suitable mesh size and refinement techniques were adopted. The technical features of the analyzed models are summarized in Table 2.

The closing phase of the chewing cycle was analyzed. Solid food (apple pulp [29]), with Young's modulus and Poisson's ratio of $3.41 \mathrm{MPa}$ and 0.10 , respectively, was modelled onto the palatal crown surface (Fig. 1). Slide-type contact elements were used between the tooth surface and the food. In addition, "freeze" type was selected as contact condition between each part of the post restoration (i.e., cement, periodontal ligament, post, dentin, enamel).

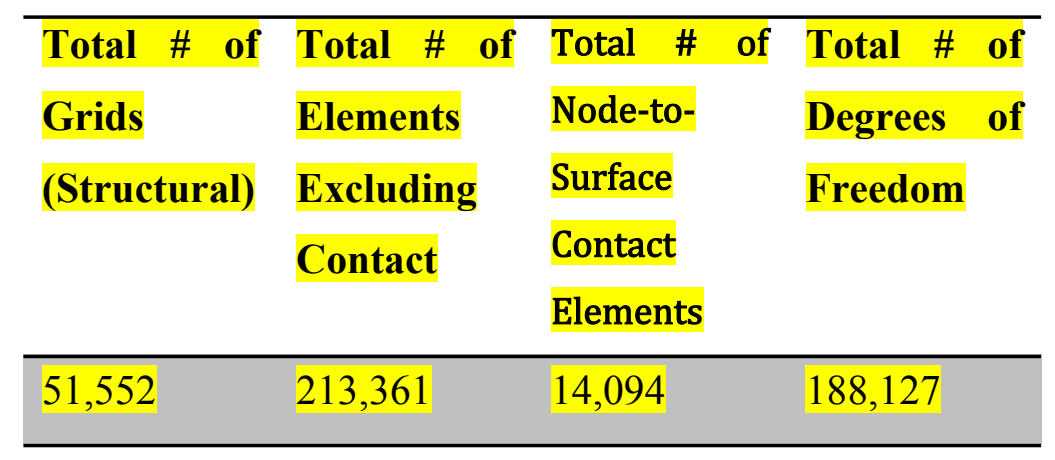

Table 2 -Technical features for the analyzed tooth models.

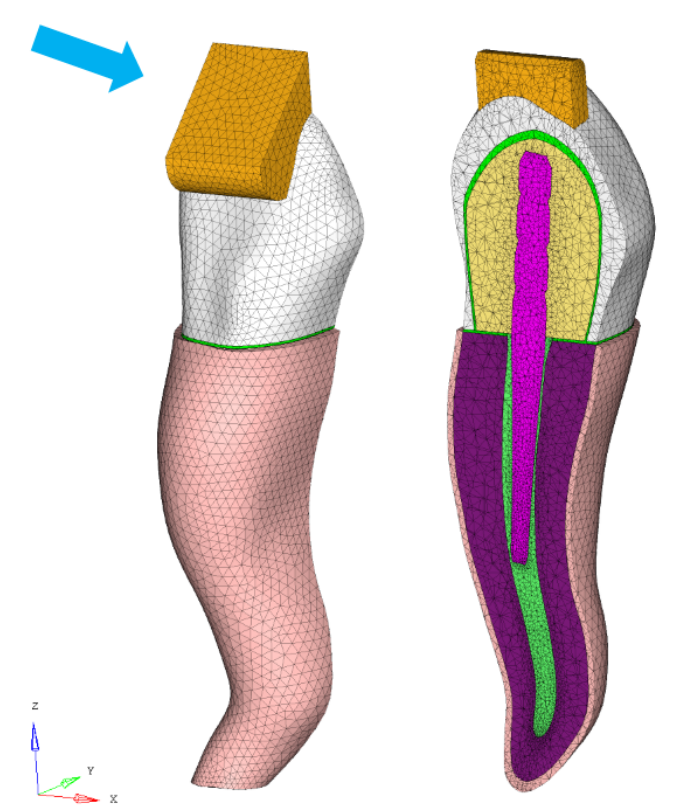

Fig. 1 - FE model according to the components of the constructed geometric models, mechanical properties and technical features. 
In the FE models of the post-restored tooth, in all directions, constraints were applied for nodal displacements on the external surfaces of the periodontal ligament. A load of $50 \mathrm{~N}$ was applied at $45^{\circ}$ to the longitudinal axis of the tooth, acting on the palatal surface of the crown [29]. Linear static analyses were performed with a non-failure condition since linear elastic behavior was assumed for all components. In the different models, the maximum principal stress distribution was evaluated along the post and at the interface between the post and the surrounding structure.

\section{Results}

The maximum principal stress distributions were reported in the abutment, post, post cement, root and periodontal ligament (Fig. 2). Cross sections were considered along the buccolingual direction for all the restored tooth models.
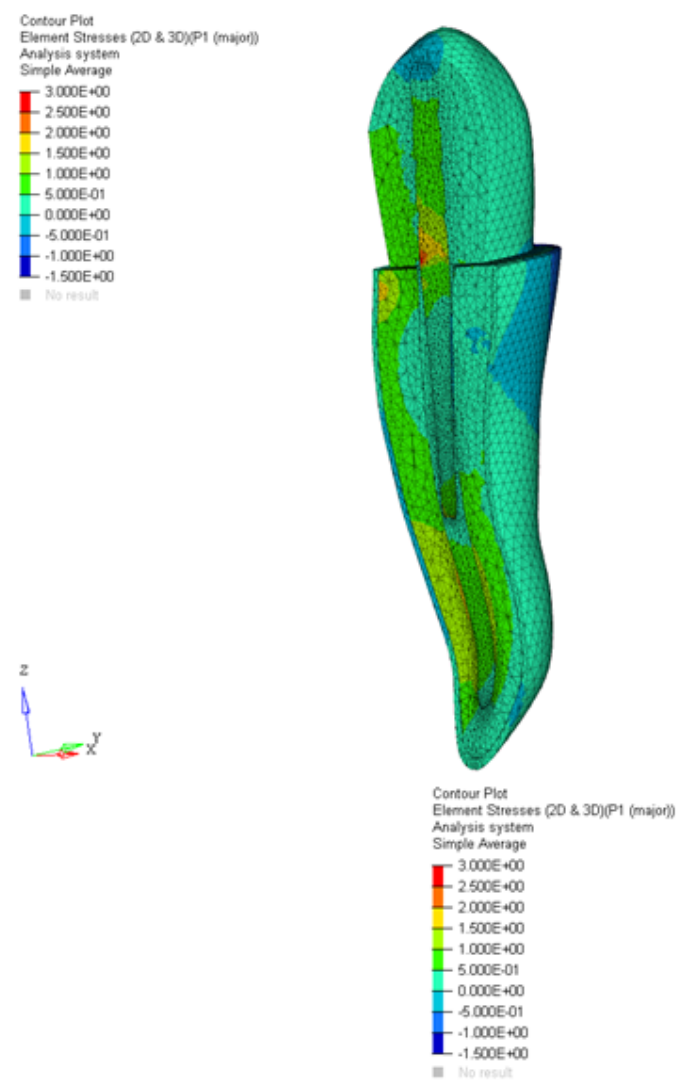

Model A
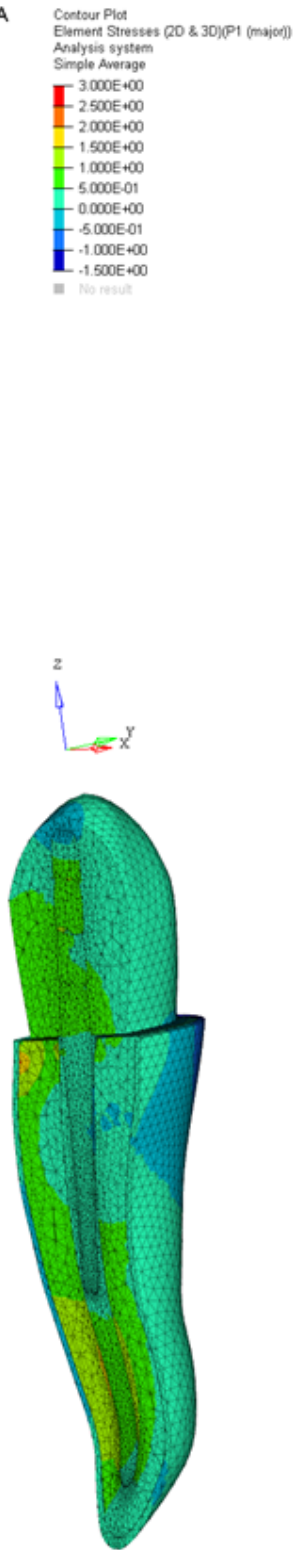

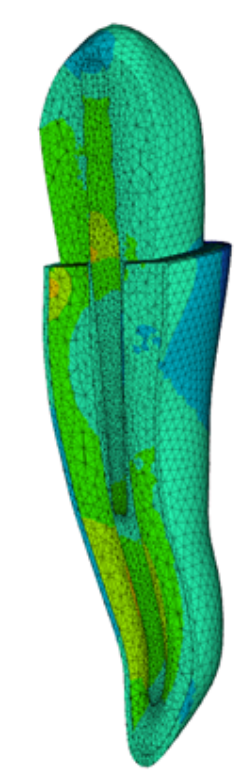

Model C

Model B

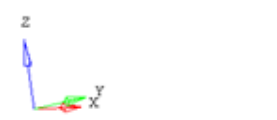

Fig. 2 - Maximum principal stress distribution (MPa) in the post-restored tooth: model A, model B and model C. 
Some differences were observed in terms of stress distribution among the models. A similar stress distribution pattern was found for Model A and B, where the highest stress regions were evident along the post near the cervical margin of the tooth. However, compared to model B, a higher stress concentration was found for model A.

Unlike models A and B, no significant stress concentration was found for model C. So among the analyzed models, the most uniform stress distribution was obtained for the post $\mathrm{C}$.

For all the investigated models, the stress distribution along the post was reported in Fig. 3.

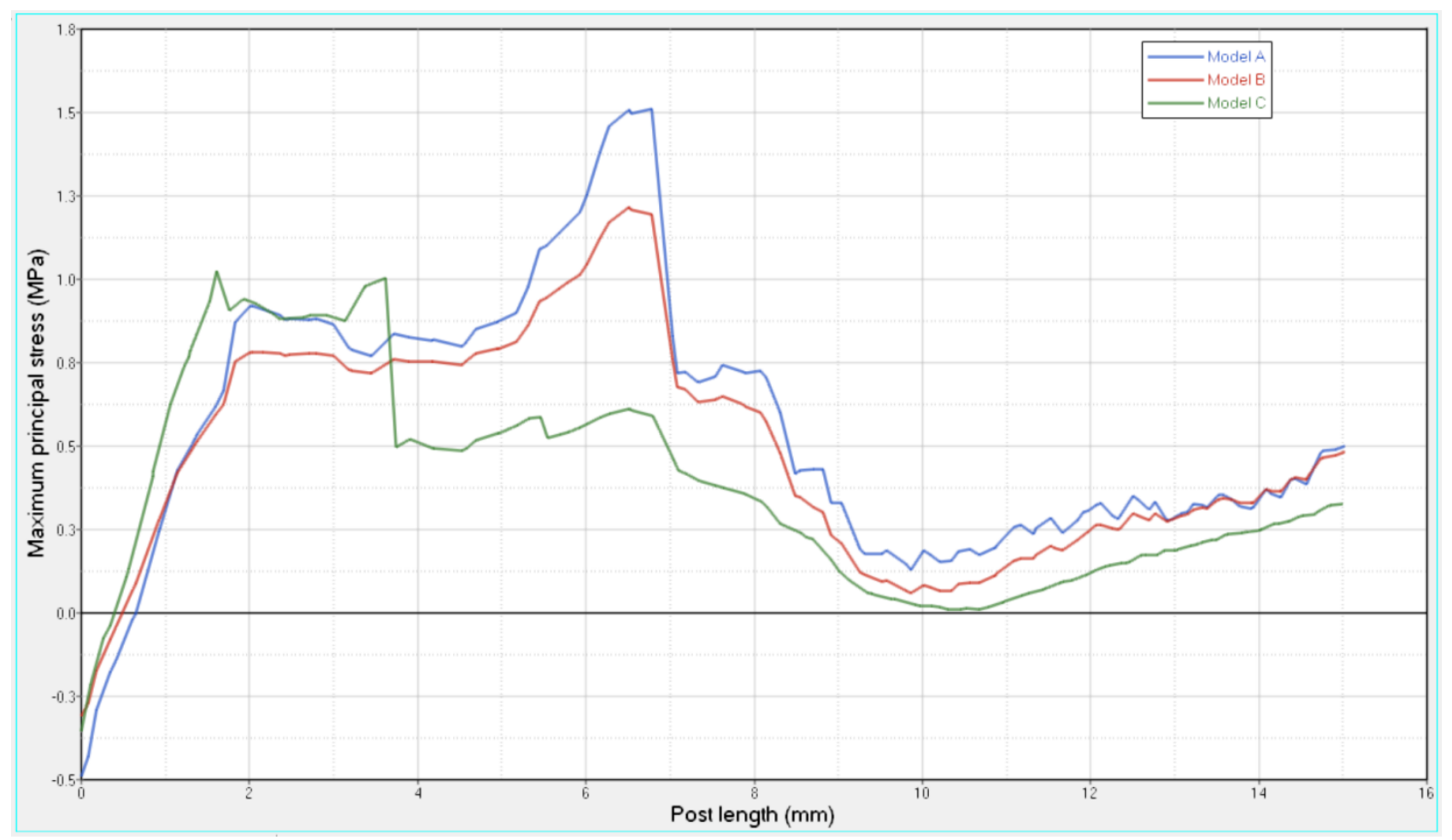

Fig. 3 - Maximum principal stress distribution along the center of the post from the coronal to the apical part.

Even though no great differences were found for all the models in the coronal region of the post, a maximum principal stress concentration was clearly observed along the post in models A and B. In contrast, consistently lower values of the stress were obtained for model C.

The stress distribution was also evaluated at the interface between the post and the surrounding structures (Fig. 4). 


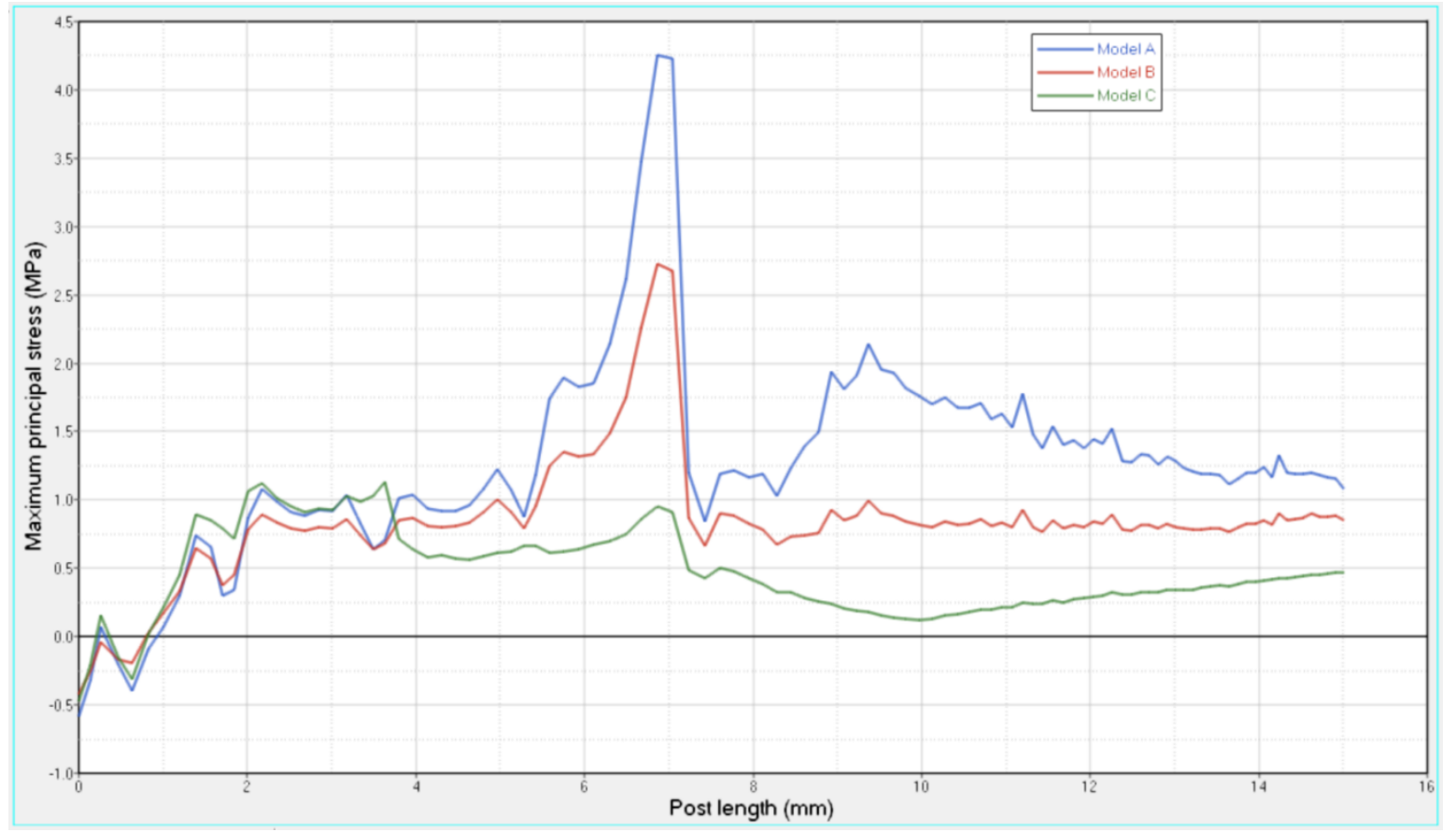

Fig. 4 - Maximum principal stress distribution at the interface between the post and surrounding structures from the coronal to the apical part.

For all three models, stress at the coronal area was initially low and then it increased towards the cervical margin of the tooth. As expected, high stress gradients were evident for models A and B. Successive changes and fluctuations up to the apical end were also much more marked for models $\mathrm{A}$ and $\mathrm{B}$. By contrast, model $\mathrm{C}$ showed gradual changes and stresses that were less than with models A and B (Fig. 4).

The differences were also analyzed via a cross section at the tooth cervical margin (Fig. 5).
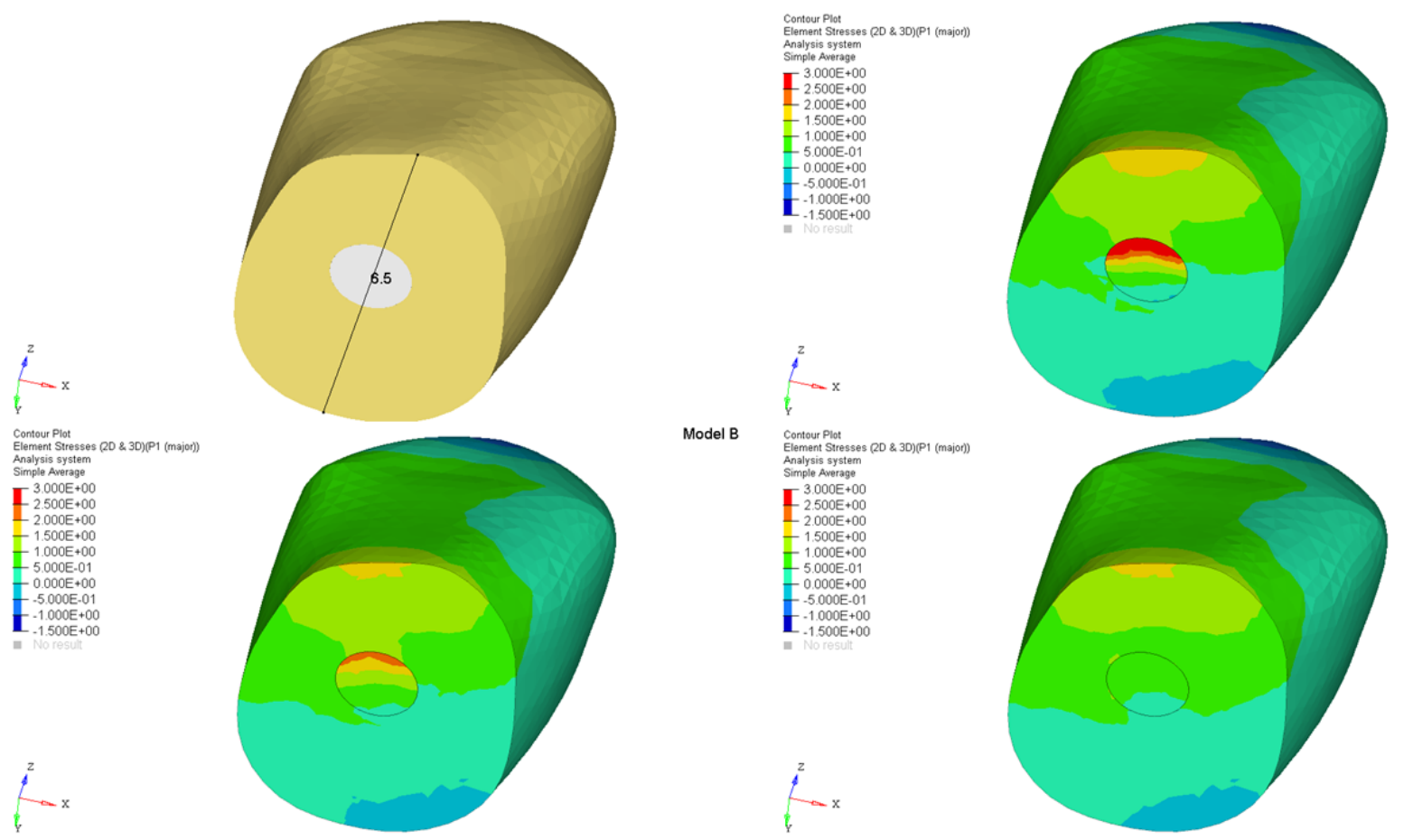
Fig. 5 - Schematic representation of the analyzed cross section at the cervical margin of the tooth (upper left) and maximum principal stress distribution.

The maximum principal stress distribution in the tooth cervical margin section, along the direction indicated by the black line in Fig. 5 (upper left), was reported in Fig. 6.

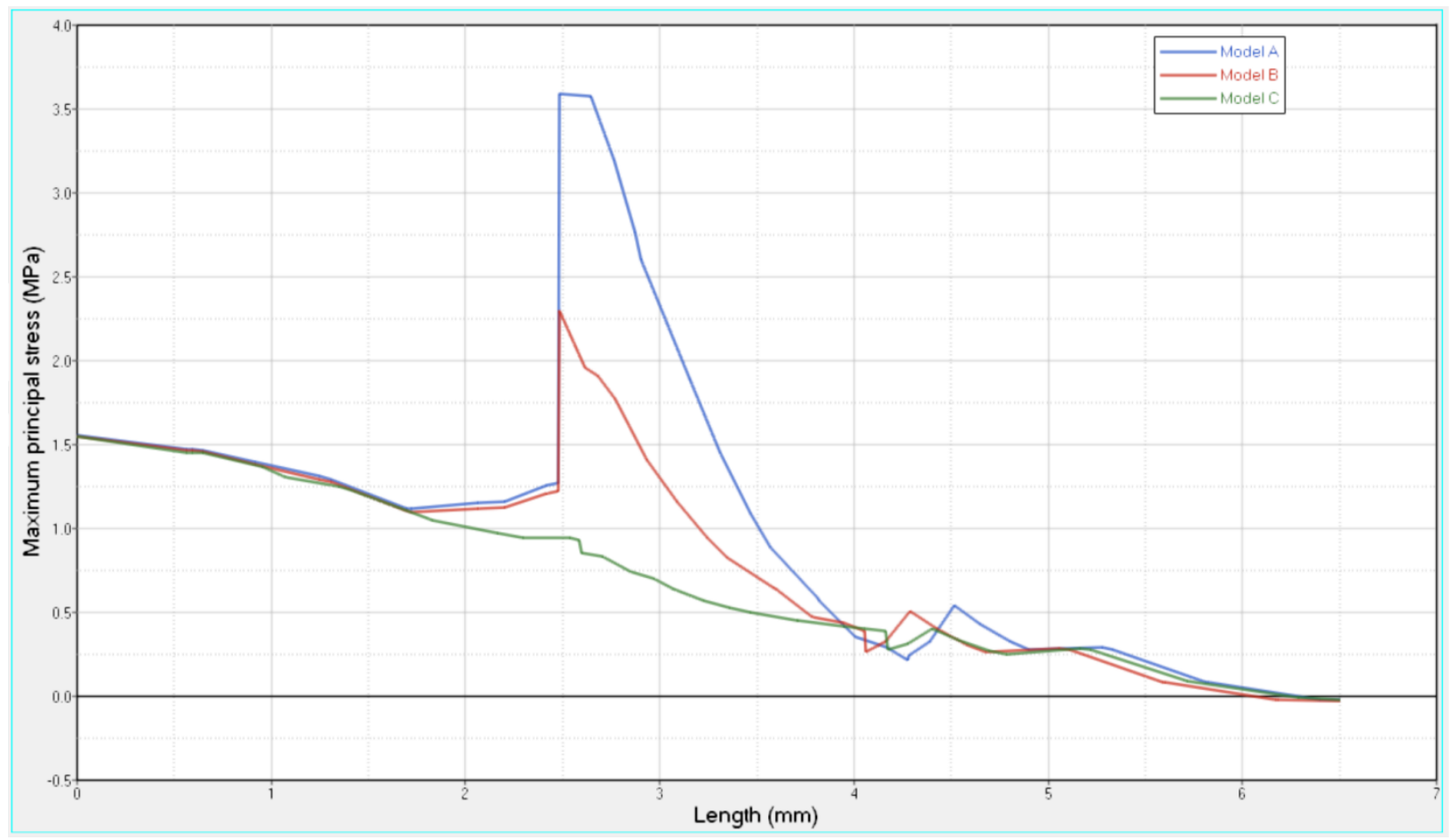

Fig. 6 - Maximum principal stress distribution at the interface between the post and the surrounding structure. A section was analyzed at the cervical margin of the tooth and the stress distribution was evaluated along the direction indicated by the black line in Fig. 5, (upper left).

From 0 to $6.5 \mathrm{~mm}$ along the considered direction (black line in Fig. 5), stresses decreased for model $\mathrm{C}$, whereas high stress gradients were evident for models $\mathrm{A}$ and $\mathrm{B}$ at the interface between the post and the surrounding structure (Fig. 5 and Fig. 6). Specifically, at $2.5 \mathrm{~mm}$ along the considered direction, a stress of 0.9 MPa was found for model $\mathrm{C}$, whereas 3.6 MPa and 2.3 MPa were found for models A and B, respectively.

\section{Discussion}

The important role of CAD-FE modeling and experimental methodologies to analyze the mechanical behavior, stress and strain distributions, has been recognized in different fields [29, 37-42]. The biomechanical behavior of a restored tooth is altered if a dental post with high modulus construction material is employed and vertical root fractures generally occur $[3,34]$. 
Currently, post-core systems consisting of prefabricated fiberglass post and resin core are used to prevent catastrophic root fracture [30].

Scientific works on the performance of post- and core- systems are constantly increasing [43]. Since the beginning of the 90 s a great amount of research has been devoted to the development of composite posts with several shapes using different kinds of fibers (from carbon to glass to quartz). Consequently, clinical procedures for restoring endodontically treated teeth have been properly modified [44, 45]. However, even if many laboratory and clinical studies were performed in this field, there are still no precise recommendations [45]. Anyway, the selection of the fiber post and the proper preparation of the root canal are the first steps. The fiber post must be adequately bonded with an adhesive resin cement as well as with recently developed self-adhesive cements, which offer the advantage of ease of use [45]. The post must be long enough and must extend properly to retain the core. Finally, the procedure includes the placement of a crown [45].

The quality of composite posts is clearly determined by the manufacturing process and widely varies according to the distribution and packing of the fibers, fiber and matrix properties, fibermatrix combination [46]. The choice of a post arises from different principles such as the preservation of tooth structure, resistance and retention, retrievability and failure mode [47]. Concerning retention form, post geometry is important (i.e., taper, length and diameter) as well as surface texture, luting agent and passivity [47].

The selection of a post is determined by functional demands and remaining tooth structure. Carbon or glass fiber posts are generally required in the case of minimal radicular tooth structure [47]. A retrospective study performed on patients with teeth restored using carbon fiber-reinforced epoxy resin posts showed interesting clinical results and no root fractures were observed. [47,48].

Carbon-based and glass fiber posts were also employed for the restoration of pulpless teeth $[47,49]$. Moreover, over a 30-month period the acceptability of quartz fiber-reinforced epoxy posts was evaluated in patients with endodontically treated teeth and a failure percentage of $1.7 \%$ was found $[47,50]$. Anyway, fiber post failures were more associated to the detachment or displacement of post and crown or device decementation than root fractures, which is a common failure related to the use of metal posts [47].

Posts fabricated from quartz fiber- or glass fiber-reinforced composites have an elastic modulus which is lower than those of carbon fiber-reinforced posts [30,46]. Furthermore, the favorable optical properties (i.e., translucency) of quartz- and glass- fiber posts provide their ability to conduct light and allow to achieve the desired aesthetic results, as well as high quality restorations.

Even though it has been frequently reported that posts could enhance the fracture resistance in endodontically treated teeth, the preparation of the post space represents a crucial point as it 
may lead to potential root fracture [47,51]. In this context, many studies were carried out to compare the fracture resistance of endodontically treated teeth [47]. In particular, a clinical evaluation of the use of fiber posts and direct resin restorations was also performed [47,52]. At 6, 12, 24 and 30-month recall, the longevity of the fiber post/direct resin restoration was assessed. It was demonstrated that fiber posts associated to direct resin restorations may be considered a faster therapeutic option, which is able to conserve the remaining tooth structure in the short term, achieving a good patient compliance [47,52].

However, it has been demonstrated that failure of teeth with fiber posts are less catastrophic if compared to metal posts, and failures are generally related to technical errors made during the cementation procedure. A thicker layer of cement is generally required for prefabricated fiber posts in comparison to metal ones [47,53].

Taking into the above reported concepts and considerations, an ideal dental post should not weaken the root while stabilizing the core [3,54] During loading, stress transfer to dentin occurs through the core and post system. Stress concentration normally occurs at the cervical and apical regions of the tooth. In compromised tooth structure, if an increase in flexure causes stress concentration at the cervical region, the post characteristics and tapering of the root canal may generate high stress concentrations in the apical region $[3,55,56]$, caused by stiffness mismatch between post and surrounding structures, [3,57]. For this reason, an ideal post should have a stiffness decreasing from coronal to apical [3].

Previous FE research considered the effect of inhomogeneous dental posts on stress distributions in tooth root and interfaces via an equation expressing the elastic modulus and Poisson's ratio as a function of the distance to the neutral axis of the post [34].

In the present work, conceptual posts designs were evaluated using the characteristic mechanical properties of polyetherimide (PEI) with carbon (C) and glass (G) fibers. Such CG/PEI composites were already produced for applications in orthopedics via hand lay-up techniques, compression molding and water jet technology [35,36].

For our three model C-G/PEI composite posts, the greatest maximum principal stresses were obtained for models A and B along the post near the cervical margin of the tooth (Fig. 2). However, model $\mathrm{C}$ showed no significant stress concentration (Fig. 2). This difference was evidently due to the functionally graded structural design of post $\mathrm{C}$. The possibility of modulating the specific distance of carbon and glass fiber-reinforced plies from the middle plane in the coronal-apical direction, together with the presence of only glass fiber-reinforced plies at the apical end of the post, should help to minimize stress concentrations. Fig. 3 demonstrated a better stress distribution for post $\mathrm{C}$ in comparison to Posts $\mathrm{A}$ and $\mathrm{B}$. This trend was confirmed in Fig 4. 
Further analysis, of the maximum principal stress distribution in a cross section at the cervical margin of the tooth along a specific direction (Fig. 5 and Fig. 6), also showed higher stress gradients for models $\mathrm{A}$ and $\mathrm{B}$ compared to $\mathrm{C}$.

Thus, in the restored tooth the C-G/PEI post with a Young's modulus varying in the coronalapical direction affected the maximum principal stress distribution.

Although the present study provided an assessment of conceptual designs of dental posts consisting of polyetherimide (PEI) reinforced with carbon (C) and glass (G) glass fibers in endodontically treated anterior teeth using FE analysis, a computer simulation is always unable to include all of the factors in the oral environment. As an example, saliva, water and blood can contaminate and degrade the post-dentin bonding [30] in clinical conditions. Therefore, clinical studies are needed to verify and supplement the current research.

In addition, some potential limitations of the present research were: (i) the constant value assumed for the Young's modulus of the periodontal ligament, (ii) the linear static analyses performed considering a non-failure condition and (iii) the approach related to the conceptual design of the C-G/PEI posts, which depended upon experimental results obtained previously $[35,36]$.

Finally, it is worth remembering that as endodontically treated teeth is one of the most investigated and controversial topics in dentistry, contradictory opinions and questions still remain about materials and devices as well as clinical procedures $[45,47]$.

\section{Conclusions}

Within the limitations of the present study, the following conclusions were drawn:

1. Conceptual designs of $\mathrm{C}-\mathrm{G} / \mathrm{PEI}$ posts were investigated including one design that optimized the stress distribution in endodontically treated anterior teeth.

2. The C-G/PEI with a modulus varying from 57.7 to $9.0 \mathrm{GPa}$ in the coronal-apical direction provided the most uniform stress distribution with no stress concentration.

\section{Acknowledgment}

Mr. Rodolfo Morra (Institute of Polymers, Composites and Biomaterials - National Research Council of Italy) is acknowledged for providing information on the mechanical test methods employed in the previous study related to the development of C-G/PEI composites.

\section{References}

1. Assif D, Bitenski A, Pilo R, Oren E. Effect of post design on resistance to fracture of endodontically treated teeth with complete crowns. J Prosthet Dent 1993;69:36-40.

2. Torbjörner A, Fransson B. Biomechanical aspects of prosthetic treatment of structurally compromised teeth. Int J Prosthodont 2004;17:135-141. 
3. Abu Kasim NH, Madfa AA, Hamdi M, Rahbari GR. 3D-FE analysis of functionally graded structured dental posts. Dent Mater 2011;30:869-80.

4. Ausiello P, Franciosa P, Martorelli M, Watts DC. Mechanical behavior of post-restored upper canine teeth: A 3D FE analysis. Dent Mater 2011; 27:1285-1294.

5. Teixeira FB. Ideal obturation using synthetic root-filling systems: coronal sealing and fracture resistance. Prac Proc Aesthet Dent 2006;18:S7-11.

6. Ferrari M, Vichi A, Mannocci F, Mason PN. Retrospective study of the clinical performance of fiber posts. Am J Dent 2000;13 (May (Special Issue)):9B-13B.

7. Wendt Jr SL, Harris BM, Hunt TE. Resistance to cusp fracture in endodontically treated teeth. Dent Mater 1987;3:232-5.

8. Salis SG, Hood JA, Kirk EE, Stokes AN. Impact-fracture energy of human premolar teeth. J Prosthet Dent 1987;58:43-8.

9. Ausiello P, Davidson CL, Cascone P, DeGee AJ, Rengo S. Debonding of adhesively restored deep Class II MOD restorations after functional loading. Am J Dent 1999;12:84-8.

10. Cobankara FK, Unlu N, Cetin AR, Ozkan HB. The effect of different restoration techniques on the fracture resistance of endodontically-treated molars. Oper Dent 2008;33:526-33.

11. Kivanc, BH, Alac,am T, Görgül G. Fracture resistance of premolars with one remaining cavity wall restored using different techniques. Dent Mater J 2010;29:262-7.

12. Santana FR, Castro CG, Simamoto-Júnior PC, Soares PV, Quagliatto PS, Estrela C, et al. Influence of post system and remaining coronal tooth tissue on biomechanical behaviour of root filled molar teeth. Int Endod J 2011;44:386-94.

13. D’Arcangelo C, De Angelis F, Vadini M, D'Amario M, Caputi S. Fracture resistance and deflection of pulpless anterior teeth restored with composite or porcelain veneers. J Endod 2010;36:153-6.

14. Akkayan B, Gülmez T. Resistance to fracture of endodontically treated teeth restored with different post systems. J Prosthet Dent 2002;87:431-7.

15. Lanza A, Aversa R, Rengo S, Apicella D, Apicella A. 3D FEA of cemented steel, glass and carbon posts in a maxillary incisor. Dent Mater 2005;21:709-15.

16. Zarone F, Sorrentino R, Apicella D, Valentino B, Ferrari M, Aversa R, et al. Evaluation of the biomechanical behavior of maxillary central incisors restored by means of endocrowns compared to a natural tooth: a 3D static linear finite elements analysis. Dent Mater 2006; 22:1035-44.

17. Sorrentino R, Salameh Z, Apicella D, Auriemma T, Zarone F, Apicella A, et al. Threedimensional finite element analysis of stress and strain distributions in post-and-core treated maxillary central incisors. J Adhes Dent 2007;9:527-36.

18. Belli S, Eraslan O, Eskitascioglu G, Karbhari V. Monoblocks in root canals: a finite elemental stress analysis study. Int Endod J 2011;20 (April), doi:10.1111/j.1365-2591.2011.

19. Dejaka B, Młotkowski A. The influence of ferrule effect and length of cast and FRC posts on the stresses in anterior teeth. Dent Mater 2013;29;e227-e237.

20. Fernandes AS, Shetty S, Coutinho I. Factors determining post selection: a literature review. J. Pros. Dent. 2003; 90:556-62.

21. Hsu ML, Chen CS, Chen BJ, Huang HH, Chang CL. Effects of post materials and length on the stress distribution of endodontically treated maxillary central incisors: a 3D finite element analysis. J Oral Rehabil 2009;36:821-30.

22. Juloski J, Radovic I, Goracci C, Vulicevic ZR, Ferrari M. Ferrule effect: a literature review. J. Endodont. 2012;38:11-9.

23. Stankiewicz N, Wilson P. The ferrule effect. Dental Update 2008; 35, 222-4, 7-8. 
24. Goracci C, Ferrari M. Current perspectives on post systems: a literature review. Austr. Dent. J. 2011;56:77-83.

25. Stankiewicz NR, Wilson PR. The ferrule effect: a literature review. Int. Endod. J. 2002;35, 575-581.

26. Lima AF, Spazzin AO, Galafassi D, Correr-Sobrinho L, Carlini-Junior B. Influence of ferrule preparation with or without glass fiber post on fracture resistance of endodontically treated teeth. J. Applied Oral Sci. 2010;18:360-3.

27. Aykent F, Kalkan M, Yucel MT, Ozyesil AG. Effect of dentin bonding and ferrule preparation on the fracture strength of crowned teeth restored with dowels and amalgam cores. J. Pros. Dent. 2006; 95:297-301.

28. Pereira JR, de Ornelas F, Conti PC, do Valle AL. Effect of a crown ferrule on the fracture resistance of endodontically treated teeth restored with prefabricated posts. J. Pros. Dent. 2006;95:50-4.

29. Ausiello P, Ciaramella S, Martorelli M, Lanzotti A, Zarone F, Watts DC, Gloria A. Mechanical behavior of endodontically restored canine teeth: Effects of ferrule, post material and shape. Dent Mater 2017;33(12):1466-72.

30. Lee K-S, Shin J-H, Kim J-E, Kim J-H, Lee W-C, Shin S-W, Lee J-Y, Biomechanical evaluation of a tooth restored with high performance polymer PEKK post-core system: A 3D finite element analysis. BioMed research international 2017; (2017).

31. Cheleux N, Sharrock P J, Mechanical properties of glass fiber-reinforced endodontic posts. Acta Biomater 2009; 5(8):3224-3230.

32. Sakaguchi R L, Powers J M, Craig's restorative dental materials-e-book. Elsevier Health Sciences: 2012.

33. Craig R, Peyton F, Elastic and mechanical properties of human dentin. J Dent Res 1958; 37(4):710-718.

34. Mahmoudi M, Saidi AR, Amini P, Hashemipour MA. Influence of inhomogeneous dental posts on stress distribution in tooth root and interfaces: Three-dimensional finite element analysis. J Prosthet Dent 2017;118(6):742-751

35. De Santis R, Ambrosio L, Nicolais L. Polymer-based composite hip prostheses. J Inorg Biochem 2000;79:97-102.

36. De Santis R, Gloria A, Ambrosio L. Composite materials for hip joint prostheses. In: L. Ambrosio editor. Biomedical Composites 2nd ed. Elsevier Ltd. 2017. p. 237-259.

37. Rodrigues FP, Li J, Silikas N, Ballester RY, Watts DC. Sequential software processing of micro-XCT dental-images for 3D-FE analysis. Dent Mater 2009;25(6):47-55.

38. Ausiello P, Ciaramella S, Garcia-Godoy F, Martorelli M, Sorrentino R, Gloria A. Stress distribution of bulk-fill resin composite in class II restorations. Am J Dent. 2017 August; 30(4):227-232.

39. Ausiello P, Ciaramella S, Martorelli M, Lanzotti A, Gloria A, Watts DC. CAD-FE modeling and analysis of class II restorations incorporating resin-composite, glass ionomer and glass ceramic materials. Dent Mater 2017;33(12):1456-65.

40. Maietta S, Russo T, De Santis R, Ronca D, Riccardi F, Catauro M, Martorelli M, Gloria A. Further Theoretical Insight into the Mechanical Properties of Polycaprolactone Loaded with Organic-Inorganic Hybrid Fillers. Materials 2018; 11(2):312; DOI:10.3390/ma11020312.

41. Martorelli M, Maietta S, Gloria A, De Santis R, Pei E, Lanzotti A. Design and analysis of 3D customized models of a human mandible. Procedia CIRP 2016; 49:199-202.

42. Caputo F, De Luca A, Greco A, Maietta S, Marro A, Apicella A. Investigation on the static and dynamic structural behaviours of a regional aircraft main landing gear by a new numerical methodology. Frattura Integr Strutt, 2018; 12(43):191-204. 
43. Cagidiaco MC, Radovic I, Simonetti M, Tay F, Ferrari M. Clinical performance of fiber post restorations in endodontically treated teeth: 2-year results. Int $\mathrm{J}$ Prosthodont 2007;20(3):293-8.

44. Grandini S, Sapio S, Simonetti M. Use of anatomic post and core for reconstructing an endodontically treated tooth: a case report. J Adhes Dent 2003;5(3):243-7.

45. Wilson P D, Wilson N, Dunne S. Manual of Clinical Procedures in Dentistry. Hoboken, USA: John Wiley \& Sons; 2018.

46. Manhart J. Fiberglass reinforced composite endodontic posts. Endodontic Practice. September 2009;16-20.

47. Faria AC, Rodrigues RC, de Almeida Antunes RP, de Mattos Mda G, Ribeiro RF. Endodontically treated teeth: characteristics and considerations to restore them. J Prosthodont Res. 2011;55(2):69-74.

48. Fredriksson M, Astbäck J, Pamenius M, Arvidson K. A retrospective study of 236 patients with teeth restored by carbon fiber-reinforced epoxy resin posts. J Prosthet Dent 1998;80 (2):151-157.

49. Martelli R. Fourth-generation intraradicular posts for the aesthetic restoration of anterior teeth. Pract Periodontics Aesthet Dent 2000;12(6):579-584.

50. Malferrari S, Monaco C, Scotti R. Clinical evaluation of teeth restored with quartz fiberreinforced epoxy resin posts. Int J Prosthodont 2003;16(1):39-44.

51. Göhring TN, Peters OA. Restoration of endodontically treated teeth without posts. Am J Dent 2003;16(5):313-317.

52. Grandini S, Goracci C, Tay Fr, Grandini R, Ferrari M. Clinical evaluation of the use of fiber posts and direct resin restorations for endodontically treated teeth. Int J Prosthodont 2005;18(5):399-404.

53. Boudrias P, Sakkal S, Petrova Y. Anatomical post design meets quartz fiber technology: rationale and case report. Compend Contin Educ Dent 2001;22(4):337-340.

54. Schmage P, Ozcan M, McMullan-Vogel C, Nergiz I. The fit of tapered posts in root canals luted with zinc phosphate cement: a histological study. Dent Mater 2005; 21: 787-793.

55. Kishen A. Mechanisms and risk factors for fracture predilection in endodontically treated teeth. Endod Topics 2006; 13: 57-83.

56. Kishen A, Asundi A. Photomechanical investigations on postendodontically rehabilitated teeth. J Biomed Opt 2002; 7: 262-270.

57. Genovese K, Lamberti L, Pappalettere C. Finite element analysis of a new customized composite post system for endodontically treated teeth. J Biomech 2005; 38: 2375-2389. 


\begin{tabular}{lll}
\hline Component & Young's modulus (GPa) & Poisson's ratio \\
\hline Lithium disilicate crown & 70 & 0.30 \\
Crown cement & 8.2 & 0.30 \\
Abutment & 12 & 0.30 \\
Post A & 57.7 & 0.30 \\
Post B & 31.6 & 0.30 \\
Post C & $57.7-9.0^{*}$ & 0.30 \\
Post cement & 8.2 & 0.30 \\
Root & 18.6 & 0.31 \\
Periodontal ligament & $0.15\left(\mathrm{x} \mathrm{10^{-3 }}\right)$ & 0.45 \\
Food (apple pulp) & $3.41\left(\mathrm{x} \mathrm{10^{-3 }}\right)$ & 0.10 \\
\hline
\end{tabular}




\begin{tabular}{lllll}
\hline Total \# of & Total \# of & Total \# of & Total \# of \\
Grids & Elements & Node-to- & Degrees of \\
(Structural) & Excluding & Surface & Freedom \\
& Contact & $\begin{array}{l}\text { Contact } \\
\text { Elements }\end{array}$ & \\
& & 14,094 & 188,127 \\
\hline 51,552 & 213,361 & 127 & \\
\hline
\end{tabular}

